\title{
Self-Care Agency and Affecting Factors in Patients With Chronic Obstructive Pulmonary Disease
}

\author{
Züleyha Kılıç ${ }^{1^{*}}$, Songül Göriş ${ }^{2}$ \\ ${ }^{1}$ Department of Internal Diseases Nursing, Niğde Ömer Halisdemir University, Zübeyde Hanım School of Health, \\ Niğde, Turkey \\ ${ }^{2}$ Department of Internal Diseases Nursing, Cukurova University, Faculty of Health Sciences, Adana, Turkey
}

\begin{abstract}
In the studies about self-care agency in chronic obstructive pulmonary disease (COPD) patients with a high agency of self-care have been found to be more successful at disease management. Determining the self-care agency (SCA) and affecting factors in patients with COPD are important nursing interventions in order to plan proper care and to support the SCA for patients with COPD. This study was conducted to determine SCA and affecting factors in patients with COPD.

Totally 226 patients with COPD who applied to chest diseases outpatient clinics of a governmental hospital in Turkey were recruited to the study between November 2012 and April 2013. Data were collected with a "patient identification form" which was prepared after a literature review and with the "self-care agency scale (SCAS).

According to the research results, mean score of SCA of patients with COPD was found to be $70.15 \pm 13.75$. Patients with COPD who were male, high school graduates, married, governmental officers, and who had given up smoking and who perceived their health status as good had a significantly higher level of SCA than other groups $(p<0.05)$.

İn the present study it was seen that patients' SCAS scores were at a moderate level. SCA of patients with COPD is affected by gender, education status, marital status, occupation, smoking status and perception of health. This study provides basic data for the future researches.
\end{abstract}

Key Words: Affecting factors, COPD, self care agency, patients

\section{Introduction}

Chronic Obstructive Pulmonary Disease is a disease with significant mortality and morbidity all over the world (1). People with COPD are experienced much symptoms like as dyspnea, phlegm, cough, wheezing, chest tightness, anxiety and depression (2-4). Associated with progression of disease, severity of symptoms increase; number of exacerbation and hospitalizations become more often; physical activity level and exercise capacity decrease (5,6). In this disease all the respiratory limitations, other symptoms and comorbidities reduce the health related quality of life and SCA comes up short $(7,8)$.

The concept of self-care was first developed by Orem and published in 1959. Self-care is defined as carrying out one's health activities in order to sustain life, health and wellness and SCA is the power to engage in action. There is a tight relationship between health and SCA $(9,10)$. In the studies about SCA in chronic diseases, patients with a high agency of self-care have been found to be more successful at disease management $(11,12)$. In a systematic review it is shown that self management interventions improve health related quality of life, reduce hospital admissions and decrease dyspnea in individuals with COPD (13). It was identified in the study of Güner and Kaymakç1 that as health promotion life style profile increased, SCA increased and as sel SCA increased, health promotion life style profile significantly increased (14).

Self-care agency exists in all patients with various degrees (9). When self-care needs of patients with COPD exceed SCA, they feel the need of nursing interventions. Nursing, according to Orem, is providing service to individuals in need of help or guidance by the nurses in line with scientific knowledge (10). Therefore nurses should know the concepts and factors related to SCA in order to plan proper care and to support the SCA for patients with COPD. In the studies emphasised that educating patients with COPD about self-care, improves selfcare ability of the patients (15). By determining the affecting factors of SCA and clearing these factors away or reducing their impact, planning individual and family education and supporting the interventions

\footnotetext{
${ }^{*}$ Corresponding Author: Züleyha Kılıç, Department of Internal Diseases Nursing, Niğde Ömer Halisdemir University, Zübeyde Hanım School of Health, 51100, Niğde, Turkey 
intended to increase SCA are important nursing interventions. In addition, by using the SCAS, SCA of COPD patients should be evaluated at regular intervals and should take the necessary measures for risk groups.

Although there are numerous studies in the literature on the SCA in individuals with chronic disease $(11,12,16)$, there are limited number of studies on this topic in individuals with COPD $(8,17)$. This study was conducted to determine SCA and affecting factors in patients with COPD.

\section{Material and Methods}

The present study was conducted to determine SCA and affecting factors in patients with COPD.

Study Design: The study had a descriptive and crosssectional design.

Sample: Research data were collected between November 2012 and April 2013 in the Chest Diseases out patients clinics at a State Hospital in Turkey. The sample of the study consisted of 226 patients who were conscious and had cognitive adequacy to answer the questions, who could communicate verbally, accepted to participate, who have been diagnosed 6 months ago and, who were in stage II, III and stage IV of COPD were recruited. In this study level of COPD stage were classified according to the spirometric parametres.

Instruments: Data of the research were collected with Patient Information Form which was prepared through literature review $(8,11,12,17)$, by the researchers to determine socio-demographic characteristics, smoking status and chronic conditions and SCAS.

Data collection tools (Patient Information Form and SCAS) were administered by the researcher using a face to face interview technique. Data were collected in a silent ambiance (in another out-off service outpatient clinic or secretary room) to minimize the factors that affect data collection process. The interviews' durations were 15-20 minutes.

\section{Patient Information Form}

The patient information form consisted of sociodemographic questions such as age, gender, education status, occupation, marital status, residence, smoking status and the disease.

Self-Care Agency Scale

Self-care agency scale (SCAS) was developed by Kearney and Fleischer (18) and the reliability and validity study for Turkey was conducted by Nahcivan (19). This scale in which patients evaluate their own capabilities or abilities to realize self-care activities includes 35 items. Every statement is scored from 0 to 4 within a 5 -likert type scale. The scores are aligned as the following; 0 means (does not describe me at all), 1 means (does not describe me much), 2 means (do not know), 3 means (describes me a little), 4 means (describes me a lot). Eight of the statements (3, $6,9,13,19,22,26,31)$ are evaluated negatively and scores are inverted. The maximum score from the scale is 140 . The more score increases, the more SCA of patients increases. The Cronbach's alpha reliability coefficient of the scale in Nahcivan's study is 0.89 . In the current study, the Cronbach's alpha was calculated as 0.82 .

Ethical Consideration: Study was started after taking ethical approval from Ethical Committee of Niğde University and institutional permission from Provincial Health Care Center. Participants were informed about the study and their verbal and written consent were obtained.

Data Analysis: Data were analysed with IBM SPSS Statistics 21 package program. Number $(n)$, percentage $(\%)$, mean $(\bar{X})$ and standard deviation (SD) of the data were shown. Normal distribution of the data was tested with Shapiro-Wilk test. Two groups were compared with independent samples $t$ test and one way ANOVA was used for multiple group comparisons. $(p<0.05)$ was set as statistically significant.

\section{Results}

In this study, mean age of the participants was $65.89 \pm 10.09$ years within the range of 33-88 years. Duration of diagnosis was between $0.50-35.00$ years and mean duration of diagnosis was $9.31 \pm 7.22$ years. Total score of SCAS ranged between 34.00-109.00 and mean total score of SCAS was $70.15 \pm 13.75$ (Table 1). Of the patients with COPD, 62.4\% were male, $51.3 \%$ were elementary school graduates, $79.6 \%$ were married, $41.6 \%$ were farmers and $40.3 \%$ lived in town. Of the participants, $47.8 \%$ gave up smoking, $38.9 \%$ had a 5 -year COPD diagnosis, $46.0 \%$ were in stage IV of COPD, $58.8 \%$ had chronic diseases other than COPD, and 45.6\% perceived their health as bad (Table 2).

Table 3 shows the mean SCAS score of patients with COPD in terms of some characteristics. It was determined that mean score of SCA of patients with an education status of high school and higher, male, married and governmental officer higher than the other groups $(p<0.05)$. Mean SCAS score of participants who have given up smoking was found to be significantly higher than participants who never smoked and who were still smoking $(p<0.05)$. Mean 
Table 1. Mean, min.-max. and median levels of some characteristics of patients with COPD $(n=226)$

\begin{tabular}{lcccc}
\hline Variables & $\bar{X} \pm$ SD & Min.-Max. & Median & $25 \%-75 \%$ \\
\hline Age & $65.89 \pm 10.09$ & $33.00-88.00$ & 67.00 & $60.00-74.00$ \\
Duration of diagnosis (year) & $9.31 \pm 7.22$ & $0.50-35.00$ & 10.00 & $3.00-15.00$ \\
Score of self-care agency & $70.15 \pm 13.75$ & $34.00-109$ & 69.50 & $60.00-81.00$ \\
\hline
\end{tabular}

score of SCAS of patients who perceived their health as good was significantly higher in comparison to the other groups $(p<0.05)$ (Table 3).

\section{Discussion}

Self-care agency is an important concept in self-care comprehension, including the arrangement of selfcare behaviours to promote and maintain a healthy life (10). In this study, mean total score of SCAS in patients with COPD was $70.15 \pm 13.75$. In our study most of the patients with COPD (87.6\%) lived many symptoms like intolerable dyspnea due to stage III and stage IV of COPD. (In this study level of COPD stage were classified according to the spirometric parametres.)

Patients suffering from dyspnea have a fear of being unable to breathe or bing out of breath. They might avoid performing the self-care activities. Therefore SCA is negatively affected. In another study on SCA in patient with COPD mean score of SCA of women patients is $74.25 \pm 30.22$ while mean score of SCA of men is $78.14 \pm 24.49$ (8).

Studies on SCA of patients with different chronic diseases have shown that SCAS score was $83.90 \pm 11.39$ in patients with insulin dependent diabetes (11), 109.43 in patients with liver cirrhosis (20) and $103.87 \pm 19.31$ in patients with hypertension (21). In our study, we determined that SCA of individuals with COPD was significantly lower than patients with other chronic diseases. The reason of that may be due to developing symptoms such as dyspnea and fatigue in individuals with COPD which inhibit to meet self-care needs of the patients.

In our study mean SCAS score of patients aged 80 years and over was lower than other age groups despite being insignificant $(p>0.05)$. Another study has suggested similarly that SCA of elderly people was lower than youngsters (8). The reasons of reduction in SCA with increasing age are change in physiological, psychological, emotional, cognitive and social areas of older people, decreasing in functional capacities, increasing in chronic diseases and passage from active position into passive position (22). In the literature some of the studies reporting age does not affect the SCA $(23,24)$.
Male patients with COPD had a significantly higher score of SCA than female patients. In the literature Yildirm et al. (8) have found that male patients with COPD had insignificantly higher SCA than female patients with COPD $(p>0.05)$. Among patients with hypertension males have been found to have higher score of SCAS compared to females (24). In the present study, male patients with COPD had higher education status, they were married and had children with high ratios compared to females $(p<0.05)$. Higher education status may increase the health awareness and being married and having children may provide social support hence SCA of those participants may have been favourably influenced. Also, the stronger role given to males in Turkish population may be the reason of male participants' taking care of their health. However, Büyükkaya et al. (20) have determined that male patients with liver cirrhosis had lower mean score of SCAS than female patients. Tel et al. (16) found that not showing the impact of gender on SCA. The study determined that patients who were secondary or high school graduates had higher SCA score than patients with lower education status. Various studies have similarly suggested the increasing se SCA along with increasing level of education status $(8,23)$. This result may be related to increased health knowledge and expectations, easier access to health care services and better economic status along with increasing education status.

Married participants were found to have significantly higher SCA score in comparison to single participants in the present study. Increased responsibilities in the family, social support from family members and sense of strong role about being parents may be the factors that positively affect SCA. In a study in individuals with COPD it was determined that there is a positive correlation between social support and self care behaviours (25).

Governmental officers were found to have higher mean score of SCAS in comparison to other occupations. Similarly, SCA of patients with DM who were governmental officers has been found to have the highest SCA than the others (11). Governmental officers have generally high education level, regular income, higher level of health awareness and lower 
Table 2. Patients characteristics $(n=226)$

\begin{tabular}{|c|c|c|}
\hline Variables & $\mathrm{n}$ & $\%$ \\
\hline \multicolumn{3}{|l|}{ Age group } \\
\hline 49 and below & 21 & 9.3 \\
\hline $50-59$ & 34 & 15.0 \\
\hline $60-69$ & 76 & 3.6 \\
\hline 70-79 & 73 & 32.3 \\
\hline 80 and ower & 22 & 9.8 \\
\hline \multicolumn{3}{|l|}{ Gender } \\
\hline Male & 141 & 62.4 \\
\hline Female & 85 & 37.6 \\
\hline \multicolumn{3}{|l|}{ Education status } \\
\hline Illiterate & 66 & 29.2 \\
\hline Literate & 35 & 15.5 \\
\hline Elementary school & 116 & 51.3 \\
\hline Secondary/High school & 9 & 4.0 \\
\hline Marital status & 180 & 79.6 \\
\hline Married & 46 & 20.4 \\
\hline \multirow{2}{*}{\multicolumn{3}{|c|}{ Occupational status $(\mathrm{n}=224)$}} \\
\hline & & \\
\hline Farmer & 94 & 41.6 \\
\hline Employee & 62 & 27.4 \\
\hline Housewife & 43 & 19.0 \\
\hline Tradesman & 17 & 7.5 \\
\hline Governmental officer & 8 & 3.5 \\
\hline \multicolumn{3}{|l|}{ Living place } \\
\hline Village & 71 & 31.4 \\
\hline Town & 91 & 40.3 \\
\hline City & 64 & 28.3 \\
\hline \multicolumn{3}{|l|}{ Smoking status } \\
\hline Not smoking & 94 & 41.6 \\
\hline Gave up smoking & 108 & 47.8 \\
\hline Still smoking & 24 & 10.6 \\
\hline \multicolumn{3}{|l|}{ Perception of health } \\
\hline Very bad & 12 & 5.3 \\
\hline Bad & 103 & 45.6 \\
\hline Moderate & 70 & 31.0 \\
\hline Good & 41 & 18.1 \\
\hline \multicolumn{3}{|c|}{ Duration of diagnosis (years) } \\
\hline$\leq 5$ & 88 & 38.9 \\
\hline $6-10$ & 67 & 29.6 \\
\hline $11-15$ & 32 & 14.2 \\
\hline$\geq 16$ & 39 & 17.3 \\
\hline \multicolumn{3}{|l|}{ Stage of the COPD } \\
\hline Stage II & 28 & 12.4 \\
\hline Stage III & 104 & 46.0 \\
\hline Stage IV & 94 & 41.6 \\
\hline \multicolumn{3}{|c|}{ Having any chronic disease other than COPD } \\
\hline \multicolumn{3}{|c|}{. } \\
\hline \multirow[t]{2}{*}{ No } & 133 & 58.8 \\
\hline & 93 & 41.2 \\
\hline
\end{tabular}


Table 3. Mean self-care agency score of patients with COPD in terms of some characteristics $(n=226)$

\begin{tabular}{|c|c|c|c|}
\hline Variables & $\bar{X} \pm \mathrm{SD}$ & $\mathrm{F} / \mathrm{t}$ & $\mathrm{P}$ \\
\hline \multicolumn{4}{|l|}{ Age group } \\
\hline 49 and below & $72.33 \pm 15.88$ & & \\
\hline $50-59$ & $71.36 \pm 13.40$ & & \\
\hline $60-69$ & $69.28 \pm 14.23$ & $F=0.91$ & 0.459 \\
\hline $70-79$ & $71.18 \pm 12.45$ & & \\
\hline 80 and ower & $65.86 \pm 14.63$ & & \\
\hline \multicolumn{4}{|l|}{ Gender } \\
\hline Male & $72.78 \pm 13.86$ & $t=-3.74$ & $<0.001$ \\
\hline Female & $65.87 \pm 12.50$ & & \\
\hline \multicolumn{4}{|l|}{ Education status } \\
\hline Illiterate & $67.12 \pm 13.39$ & & \\
\hline Literate & $68.46 \pm 13.36$ & & \\
\hline Elementary school & $71.68 \pm 13.79$ & $F=3.15$ & 0.026 \\
\hline Secondary/High school & $79.33 \pm 12.27$ & & \\
\hline \multicolumn{4}{|l|}{ Marital status } \\
\hline Married & $71.94 \pm 13.53$ & $\mathrm{t}=3.99$ & $<0.001$ \\
\hline Single & $63.15 \pm 12.40$ & & \\
\hline \multicolumn{4}{|c|}{ Occupational status $(\mathrm{n}=224)$} \\
\hline Farmer & $68.16 \pm 13.34$ & & \\
\hline Employee & $72.63 \pm 15.01$ & & \\
\hline Housewife & $67.44 \pm 11.89$ & $\mathrm{~F}=3.43$ & 0.010 \\
\hline Tradesman & $74.71 \pm 12.85$ & & \\
\hline Governmental officer & $81.75 \pm 11.76$ & & \\
\hline \multicolumn{4}{|l|}{ Smoking status } \\
\hline Not smoking & $66.13 \pm 12.50$ & & \\
\hline Gave up smoking & $73.23 \pm 14.35$ & $F=7.36$ & 0.001 \\
\hline Still smoking & $72.08 \pm 12.02$ & & \\
\hline \multicolumn{4}{|l|}{ Perception of health } \\
\hline Very bad & $69.75 \pm 12.90$ & & \\
\hline $\mathrm{Bad}$ & $65.93 \pm 13.04$ & $F=7.73$ & 0.001 \\
\hline Moderate & $72.59 \pm 12.50$ & & \\
\hline Good & $76.73 \pm 14.61$ & & \\
\hline \multicolumn{4}{|c|}{ Duration of diagnosis (years) } \\
\hline$\leq 5$ & $72.50 \pm 14.49$ & & \\
\hline $6-10$ & $67.43 \pm 12.49$ & $\mathrm{~F}=2.41$ & 0.067 \\
\hline $11-15$ & $67.34 \pm 11.53$ & & \\
\hline$\geq 16$ & $71.85 \pm 14.94$ & & \\
\hline \multicolumn{4}{|l|}{ Stage of the COPD } \\
\hline Stage II & $71.89 \pm 15.98$ & & \\
\hline Stage III & $70.77 \pm 13.82$ & $\mathrm{~F}=0.68$ & 0.507 \\
\hline Stage IV & $68.96 \pm 12.99$ & & \\
\hline \multicolumn{4}{|c|}{$\begin{array}{l}\text { Having any chronic disease other than } \\
\text { COPD }\end{array}$} \\
\hline Yes & $68.77 \pm 13.74$ & $\mathrm{t}=3.20$ & 0.069 \\
\hline No & $72.14 \pm 13.58$ & & \\
\hline
\end{tabular}


level of exposure to risk factors for disease at work which may have influenced SCA favourably.

In this study mean SCA score of participants who have given up smoking was found to be significantly higher than participants who never smoked and who were still smoking. A similar study also shows a higher SCA of patients with COPD who have given up smoking (17). This important finding may result from patients' increased health awareness which then increases SCA attitudes. However, there are also studies which do not suggest such a relationship between smoking status and SCA $(8,20)$.

In the present study mean score of SCA in patients with good health perception was higher than other groups. Yildirim et al. (8) have found out that as the health perception of patients increased, their SCA also significantly improved. This finding is emphasized that psychological well-being is an importance factor to increase SCA.

In our study it was seen that patients' SCAS scores were at a low level. SCA was influenced by gender, education status, marital status, occupation, family type, type of house, type of getting heated, smoking status and health perception condition. Participants who were male, high school graduates, married, lived in a nuclear family, lived in a concrete house, who have given up smoking and who had a better health perception had significantly higher SCA score $(p<$ 0.05). It was also determined that age, BMI, having children, number of children, duration of working, social insurance, living place, current smoking, duration of quitting smoking and quantity of smoking did not affect SCA $(p>0.05)$.

The following may be recommended throughout the results of the present study; Nurses should determine SCA of subject with COPD and take them into consideration for planning their care. Educations should be organized about self-care concept either during bachelors' education or in-service educations. Large scale studies towards SCA and affecting factors for patients with COPD should be conducted. Intervention studies should be conducted to increase SCA of patients with COPD.

\section{References}

1. 1.Global Initiative for Chronic Obstructive Lung Disease (GOLD). Global strategy for the diagnosis, management and prevention of chronic obstructive lung disease 2017. Available from http://www.goldcopd.org.

2. Cukier A, Godoy I, Costa CHD, Rubin AS, Gregorio MG, et al. Symptom variability over the course of the day in patients with stable COPD in
Brazil: a real-world observational study. J Bras Pneumol 2019; 46 (3): e20190223.

3. Kesler R, Partridge MR, Miravitlles M, et al. Symptom variability in patients with severe COPD: A pan-European cross-sectional study. Eur Respir J 2011; 37(2): 264-272.

4. Pumar MI, Gray CR, Walsh JR, Yang IA, Rolls TA, Ward DL. Anxiety and depression-Important psychological comorbidities of COPD. J Thorac Dis 2014; 6: 1615-1631.

5. Henoch I, Strang S Löfdahl CG Ekberg-Jansson A. Health-related quality of life in a nationwide cohort of patients with COPD related to other characteristics. Eur Clin Respir J 2016; 3: 31459.

6. Waschki B, Kirsten AM, Holz O, et al. Disease progression and changes in physical activity in patients with chronic obstructive pulmonary disease. Am J Respir Crit Care Med 2015; 192: 295-306.

7. Wacker ME, Jörres RA, Karch A, Koch A et al. Relative impact of COPD and comorbidities on generic health-related quality of life: A pooled analysis of the COSYCONET patient cohort and control subjects from the KORA and SHIP studies. Respir Res 2016; 17(1): 81.

8. Yıldırım A, Hacıhasanoğlu Aşılar R, Bakar N, Demir N. Effect of anxiety and depression on self-care agency and quality of life in hospitalized patients with chronic obstructive pulmonary disease: A questionnaire survey. International Journal of Nursing Practice 2013; 19: 1422.

9. Velioğlu P. Concepts and Theories in Nursing. İstanbul: Alaş Ofset 1999.

10. Orem DE. Nursing Concepts of Practice. 6th ed. St. Louis, MO: C V Mosby 2001.

11. Özkan S, Durna Z. Determination of self-care agency in patients with insülin dependent diabetes. Journal of Ege University School of Nursing 2006; 22: 121-135.

12. Sousa VD, Zauszniewski JA, Musil CM, Price Lea PJ, Davis SA. Relationships among self-care agency, self-efficacy, self-care, and glycemic control. Res Theory Nurs Pract 2005; 19: $217-$ 230.

13. Zwerink M. Brusse-Keizer P.D.L.P.M. van der Valk, et al. Self management for patients with chronic obstructive pulmonary disease. Cochrane Database Syst Rev 2014; 19: CD002990.

14. Güner Sİ, Kaymakc1 S. The examination of the relationship between health promotion life-style profile and self-care agency of women who underwent mastectomy surgery. Eastern Journal of Medicine 2014; 19: 71-78.

15. Mousing CA, Lomborg K. Self-care 3 months after attending chronic obstructive pulmonary disease patient education: a qualitative descriptive analysis. Patient Prefer Adherence 2012; 6: 19-25. 
16. Tel H, Hizmetli S, Tel H, Yıldırım M. Quality of life and self-care agency on osteoarthritis patients. Turkish Journal of Geriatrics 2011; 14: 63-67.

17. Xiaolian J, Chaiwan S, Panuthai S, Yijuan C, Lei, Y, Jiping L. Family support and self-care behavior of Chinese chronic obstructive pulmonary disease patients. Nursing and Health Sciences 2002; 4: 4149.

18. Kearney BY, Fleischer BJ. Development of an instrument to measure exercise of self-care agency. Res Nurs Health 1979; 22: 25-34.

19. Nahcivan N. A Turkish language equivalence of the exercise of self-care agency scale. Western Journal of Nursing Research 2004; 26: 813-824.

20. Büyükkaya D, Fesci H, Akdemir,N. Determine of self-care agency of patients with liver cirrhosis. Atatürk University Journal of Nursing 2006; 9: 1324.
21. Savaşan A. The Relationship between Anger and Self-Care Agency in Patients with Hypertension. Journal of Psychiatric Nurses 2009; 1: 13-17.

22. Tiftik S, Kayıs A, Inanır İ. Systemic changes in older adults, disease and the role of the nurse. Akad Geriatri 2012; 4:1-11.

23. 23. Durmaz Akyol A, Cetinkaya Y, Bakan G, Yarali S, Akkuş S. Self-care agency and factors related to this agency among patients with hypertension. J Clin Nurs 2007; 16: 679-687.

24. Bakoğlu E \& Yetkin A. The evaluation of selfcare agency of with hypertension patients. Journal of Cumhuriyet University School of Nursing 2000; 4: 41-49.

25. Kara Kaşikçi M, Alberto J. Family support, perceived self-efficacy and self-care behaviour of Turkish patients with chronic obstructive pulmonary disease. J Clin Nurs 2007; 16: 1468-78. 